\title{
Association between age factors and strategies for promoting participation in gastric and colorectal cancer screenings
}

\author{
Chisato Hamashima $^{1 *}$ D and Hiroshi Sano ${ }^{2}$
}

\begin{abstract}
Background: Despite the long history of cancer screening in Japan, the participation rates in gastric and colorectal cancer screenings have not increased. Strategies for improving the participation rates have been proposed, but differences in their effects among different age groups remain unclear.

Methods: The Japanese government conducted a national survey in all municipalities in Japan in 2010 to investigate whether the implementation of promotion strategies increased participation in cancer screening. We investigated the association between age factors and strategies for promoting participation in cancer screening based on this national survey. Multiple regression analysis with generalized linear model was performed using the participation rates in gastric and colorectal cancer screenings as dependent variables, and the following strategies for promoting participation as independent variables: 1) personal invitation letters, 2) household invitation letters, 3) home visits by community nurses, 4) screenings in medical offices, and 5) free cancer screening programs.

Results: One thousand six hundred thirty nine municipalities for gastric cancer screening and 1666 municipalities for colorectal cancer screening were selected for the analysis. In gastric and colorectal cancer screenings, the participation rates of individuals aged 60-69 years was higher than those of other age groups. Personal and household invitation letters were effective promotion strategies for all age groups, which encouraged even older people to participate in gastric and colorectal cancer screenings. Screening in medical offices and free screenings were not effective in all age groups. Home visits were effective, but their adoption was limited to small municipalities.

Conclusions: To clarify whether promotion strategies can increase the participation rate in cancer screening among different age groups, 5 strategies were assessed on the basis of a national survey. Although personal and household invitation letters were effective strategies for promoting participation in cancer screening for all age groups, these strategies equally encouraged older people to participate in gastric and colorectal cancer screenings. If resource for sending invitation letters are limited, priority should be given to individuals who are in their 50s and 60s for gastric and colorectal cancer screening.
\end{abstract}

Keywords: Gastric cancer screening, Colorectal cancer screening, Participation rate, Invitation letter, Target age group, Older people

\footnotetext{
* Correspondence: chamashi@ncc.go.jp

${ }^{1}$ Division of Cancer Screening Assessment and Management, Center for

Public Health Science, National Cancer Center, 5-1-1 Tsukiji Chuo-ku, Tokyo

104-0045, Japan

Full list of author information is available at the end of the article
} 


\section{Background}

Cancer screening is one of the major strategies for controlling cancer worldwide. To achieve the goal of reducing mortality from the target cancer, a high participation rate is required as well as quality assurance of evidence-based screening. Gastric cancer screening as a national program in Asia has been carried out only in Korea and Japan [1, 2]. However, colorectal cancer screening by fecal occult blood testing (FOBT) has been gradually adopted worldwide [1-3]. Although colorectal cancer screening has not yet been fully established compared with breast and cervical cancer screenings, some countries have already introduced organized screening which clearly define the target age group and encourage them to participate using a call/recall system [1, 3, 4]. Usually, the upper age limit in colorectal cancer screening ranges from 64 to 80 years [3].However, there is no upper age limit in the national programs for gastric and colorectal cancer screenings in Korea and Japan [1, 5].

Although there is a long history of cancer screening in Japan, there is unfortunately still no national call/recall system [5]. Therefore, the participation rates have gradually decreased or flattened in all screening programs. In fact, the national average participation rates have not increased, particularly for gastric cancer screening at 10 . $1 \%$ and for colorectal cancer screening at $21.1 \%$ in 2012 [6]. Therefore, in 2009, the Japanese government published cancer control plans and revised them in 2012, which paved the way for setting a national goal for reducing cancer mortality by improvement of cancer prevention, screening, and treatment [7]. In these plans, the goal was to achieve a participation rate of $40 \%$ for gastric and colorectal cancer screenings within 5 years, and the national government has actively encouraged improving participation rates in cancer screening [7]. Then, municipal governments have uniquely undertaken strategies for increasing the participation rate in cancer screening in accordance with their own responsibilities.

Although the incidences of gastric and colorectal cancers increase with age, individuals who are in their 50s and 60s have priory as the target populations for gastric and colorectal cancer screenings based on their incidence and productivity loss. As there is no upper age limit in Japan [5], promotion strategies for cancer screening have equally targeted all age groups. Thus, individuals aged 70 years and older can easily participate in cancer screening, as evidenced by the recent increase in their participation rate [6]. In a previous study in Japan, invitation letter and personal visits by community nurses were shown to increase participation in cancer screening [8]. However, the different effects of various promotion strategies on individuals aged 70 years older and younger remain unclear. In this article, we investigated the association between age factors and strategies for promoting participation in cancer screening based on a national survey.

\section{Methods \\ Cancer screening programs in Japan}

In Japan, the national government has defined the national policy of cancer screening programs based on the law and has selected screening methods as per evidence-based guidelines [2]. Five cancer screening programs including gastric and colorectal cancer screenings are provided by local municipal governments as financially supported by the national government. Cancer screening programs are not covered by health insurance, but are supported by tax. Gastric cancer screening using the upper gastrointestinal series with barium meal (UGI) was introduced as a national program in 1983, followed by colorectal cancer screening using FOBT in 1992 [2]. The target age groups of gastric and colorectal cancer screenings are individuals aged 40 years and older and the screening interval is every year. Most programs have been mainly provided in the form of mass screening by mobile vans and in public places including local cancer screening centers. Opportunities for cancer screening in medical offices have been mainly provided in urban areas.

\section{Data sources}

For this analysis, we used the results of 2 national surveys for all municipalities. The first is annul survey of cancer screening programs [9]. The second is a specific survey regarding the promotion plan for cancer screening in 2010 [10].

The first data source is annual reports that all municipalities submit to the national government showing the results of their cancer screening programs. The results include the total numbers of participants, positive cases of primary screening, examinees of the diagnostic examinations, and cancer detection rates. Although the total number of municipalities in 2010 was 1746, 46 municipalities failed to submit the results of their cancer screening because of the Great East Japan Earthquake [9].

Based on the cancer control plan by the national government, local municipalities have individually undertaken promotion strategies to improve participation rates in their cancer screenings. In 2010, a national survey was temporally conducted for all municipalities to investigate the effect of 'with or without the implementation' of the following promotion strategies for increasing participation in cancer screening: 1) personal invitation letters, 2) household invitation letters, 3) home visits by community nurses, 4) screenings in medical offices, and 5) free cancer screening programs [11]. These promotion strategies have often been introduced in local municipalities. Some municipalities send invitation letters directly to target individuals, or other municipalities send them to family units regardless of the 
total number of target individuals. Although cancer screening has been mainly provided as mass screening in Japan, individual participation in cancer screening at medical offices can increase access. These also correspond to the basic concept of the standard promotion strategies which are assessed by the Community Preventive Service Task Force [11] as follows: personal and household invitations as client reminder, home visits by community nurses as one-on-one education, screenings in medical offices to reduce structure barrier, and free cancer screening programs to reduce outof-pocket payments.

To refine the target municipalities for our analysis based on above-mentioned data source, the following municipalities were excluded: 1) no promotion strategies for improving the participation rate in the second survey, 2) missing or inconsistent data related to the number of participants in the first survey, 3) less than 100 participants in gastric and colorectal cancer screenings in 2010.

\section{Statistical analysis}

To investigate the associations and strategies for improving the participation rates in all cancer screenings, we defined the calculation method of the participation rate as follows: the denominator was defined as the National Census population in 2010 [12], and the numerator was defined as the number of participants in each cancer screening cited from the report on regional public health services and health promotion in 2010 [9]. The participation rates in gastric and colorectal cancer screenings were calculated by 4 age groups as follows: 40-49 years, 50-59 years, 60-69 years, and 70 years or older.

Multiple regression analysis with generalized linear model (GLM) was performed using the participation rates in gastric and colorectal cancer screenings as dependent variables, and the strategies for promoting participation as independent variables. As the participation rate ranged from 0 to 1 , binominal distribution was assumed for dependent variables. Although the participation rate was a continuous variable, ordinary least squares (OLS) assuming a normal distribution as an error term could not be used for regression analysis. Factors that affected participation rates were estimated by GLM using logit function as link function. Marginal effects, similarly to the coefficient value in OLS, represents a change in the explained variable due to one unit change in the explanatory variable in GLM. In GLM, when the marginal effect of a certain strategy is estimated as $\beta$, it means that the participation rate is increased 12 by $(\beta \times 100) \%$ points.

For all the promoting strategies consisting of personal invitation letters, household invitation letters, home visits by community nurses, screenings in medical offices, and free cancer screenings for all age groups, a dichotomous variable that takes the value 0 or 1 was used to indicate whether they are implemented. The total population of the municipalities was divided into 2 groups, namely, $\geq 30,000$ and $<30,000$ because the city and town were divided by the total population as 30,000 . The total number of medical facilities was considered as an important factor affecting cancer screening in medical facilities, which were cited from the Medical Institute Survey in 2010 [13]. The total population $(\geq 30,000$ or $<30,000)$, the total number of medical facilities per 1000 individuals aged 40 years and older, and the proportion of women were used as covariates. The estimates of all strategies were adjusted by these covariates.

Statistical analysis was performed using STATA 13.0 (STATA, College Station, TX, USA). All test statistics were two-tailed, and $P$-values $<0.05$ were considered to indicate a statistically significant difference.

\section{Results}

The selection procedure for the target population is shown in Fig. 1. From 1746 municipalities in 2010, 1639 municipalities for gastric cancer screening and 1666 municipalities for colorectal cancer screening were analyzed.

In gastric cancer screening, the participation rate of individuals aged 60-69 years was higher than the participation rate of individuals of other age groups. The female ratios were almost the same for all age groups, but statistically significant differences were shown owing to the slightly lower rates for the 60-69 age group (Table 1). The most common promotion strategy was screening at medical facilities, with $45 \%$ of the municipalities preparing the screening opportunities. Home visits by community nurses were limited to $6 \%$.

In colorectal cancer screening, the participation rate in the group consisting of individuals who were in their 60s and 70s was higher than the participation rate in the age group consisting of individuals who were in their $40 \mathrm{~s}$ and 50s (Table 2). The most common promotion strategy was screening at medical offices, with $50 \%$ of the municipalities preparing the screening opportunities. Sending personal invitation letters was performed in $38 \%$ of the municipalities for gastric and colorectal cancer screenings.

The results of the multiple regression analysis for gastric cancer screening are shown in Table 3. Home visits by community nurses were identified as the most effective promotion strategy in all age groups. Sending personal and household invitation letters were also effective in all age groups. Although sending household invitation letters was more effective in the age group consisting of individuals who were in their 40 s to 60 s, the marginal effects were similar in sending personal invitation letters and home visits by community nurses in all age groups. However, the marginal effects were limited to below $10 \%$ point. Negative effects of screening at medical offices were 


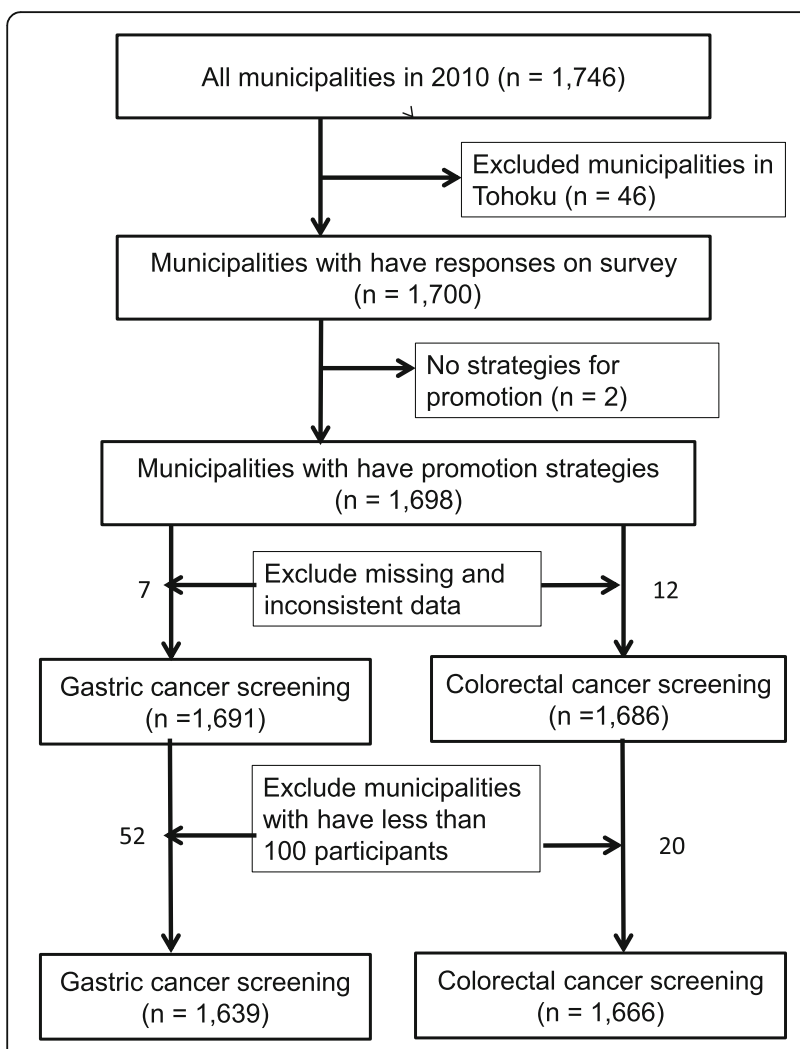

Fig. 1 Flowchart of the selection process for the target group. Although the total number of municipalities in 2010 was 1746, 46 municipalities failed to submit the results of their cancer screening because of the Great East Japan Earthquake [8]. Two municipalities were not able to conduct the above-mentioned questionnaire survey on promotion strategies for improving the participation rate. Municipalities that had missing or inconsistent data related to the number of participants were excluded as follows: 7 municipalities for gastric cancer screening and 12 municipalities for colorectal cancer screening. In addition, there were municipalities whose number of participants was less than 100, namely, 52 municipalities for gastric cancer screening and 20 municipalities for colorectal cancer screening. These municipalities were also excluded from the analysis [8] Finally, 1639 municipalities for gastric cancer screening and 1666 municipalities for colorectal cancer screening were analyzed

observed in the age group consisting of individuals who were in their $40 \mathrm{~s}$ to $60 \mathrm{~s}$, but these were not significant. The marginal effects of free screenings were not significant in all age groups.

The results of the multiple regression analysis for colorectal cancer screening are shown in Table 4. Sending personal and household invitation letters and visits by community nurses were also effective in all age groups. However, the marginal effects of sending personal and household invitation letters were higher in individuals aged 70 years and older than in individuals aged 40-69 years. The marginal effects of screening at medical offices and free screenings were not significant in all age groups.

\section{Discussion}

Although we identified that personal and household invitation letters were effective promotion strategies for increasing participation in gastric and colorectal cancer screenings [8], we obtained the same results even if the subjects were divided into 4 age groups. These results are also consistent with those of previous studies [4, 14, 15]. Sending invitation letters to the target population is a central role of the call/recall system for cancer screening programs. The results suggest that the call/recall system could be adopted to improve the participation rate in Japan. Although home visits also encouraged participation in cancer screening, a limited number of municipalities introduced this strategy mainly in rural areas whose total population was $<30,000$. Since face-toface communication is performed by community nurses, the same effects as those of a physician's recommendation can be expected.

Personal and household invitation letters had similar effects for all age groups. Client reminder was sufficient to increase the participation rate for all target populations in colorectal cancer screening [14]. However, there is still no clear upper age limit and older people can continue to participate in cancer screening. Among older veterans, it has been reported that $41 \%$ of the patients with severe comorbidity and life expectancies of less than 5 years were screened for colorectal cancer [16]. Lewis et al. also reported that older participants would continue cancer screening throughout their lives, and $43 \%$ would consider cancer screening even if their doctor does not recommend it [17]. Some older people have continued cancer screening as a matter of routine or habit, or occasionally in response to a physician's prompting and an invitation letter [18]. In gastric and colorectal cancer screenings, the main participants were individuals aged 60-69 years, and they continued to be screened even after 70 years. As a result, invitation letters encouraged older people to participate in cancer screening. If life expectancy is short, the net benefit is limited for older people [19]. Despite the high possibility of harms in the forms of overdiagnosis and complications for older people, they might still hold unrealistic expectations. As most brochures related to cancer screening tend to show favorable results of participation in cancer screening [20, 21], older people cannot easily distinguish and separate the necessity and effects of cancer screening. However, in spite of their frequent visits to the medical offices, older people who continue cancer screening still have few opportunities to be informed of the potential benefits and harms of cancer screening [18]. Informed decision making has been assumed to resolve these issues, but this has not been effective as expected [17, 18, 22]. 
Table 1 Basic characteristics of gastric cancer screening

\begin{tabular}{|c|c|c|c|c|}
\hline & Average & $95 \% \mathrm{Cl}$ & & $P$-value \\
\hline Total number of municipalities & 1639 & & & \\
\hline \multicolumn{5}{|l|}{ Participation rate (\%) } \\
\hline $40-49$ years & 13.18 & 12.60 & 13.77 & \multirow[t]{4}{*}{$<0.05$} \\
\hline $50-59$ years & 14.90 & 14.29 & 15.50 & \\
\hline $60-69$ years & 21.58 & 20.89 & 22.26 & \\
\hline$\geq 70$ years & 14.06 & 13.48 & 14.64 & \\
\hline \multicolumn{5}{|l|}{ Intervention to promote participation in cancer screening } \\
\hline Personal invitation letters & 0.384 & 0.360 & 0.407 & \multirow[t]{5}{*}{$<0.05$} \\
\hline Household invitation letters & 0.214 & 0.194 & 0.234 & \\
\hline Home visits by community nurses & 0.059 & 0.047 & 0.070 & \\
\hline Screenings at medical offices & 0.448 & 0.424 & 0.473 & \\
\hline Free screenings for all age groups & 0.081 & 0.068 & 0.094 & \\
\hline \multicolumn{5}{|l|}{ Covariate } \\
\hline$\geq 30,000$ of total population in each municipality & 0.475 & 0.450 & 0.499 & - \\
\hline Total number of medical facilities per 1000 individuals aged 40 years and older & 1.165 & 1.133 & 1.197 & - \\
\hline \multicolumn{5}{|l|}{ Percentage of women (\%) } \\
\hline $40-49$ years & 59.59 & 59.05 & 60.14 & \multirow[t]{4}{*}{$<0.05$} \\
\hline $50-59$ years & 59.82 & 59.27 & 60.38 & \\
\hline $60-69$ years & 56.01 & 55.74 & 56.28 & \\
\hline$\geq 70$ years & 60.13 & 59.92 & 60.34 & \\
\hline
\end{tabular}

Statistically significant difference based on ANOVA (analysis of variance)

Table 2 Basic characteristics of colorectal cancer screening

\begin{tabular}{|c|c|c|c|c|}
\hline & Average & $95 \% \mathrm{Cl}$ & & $P$ value \\
\hline Total number of municipalities & 1666 & & & \\
\hline \multicolumn{5}{|l|}{ Participation rate (\%) } \\
\hline 40-49 years & 15.69 & 15.04 & 16.33 & \multirow[t]{4}{*}{$<0.05$} \\
\hline $50-59$ years & 18.84 & 18.17 & 19.52 & \\
\hline $60-69$ years & 28.70 & 27.95 & 29.46 & \\
\hline$\geq 70$ years & 21.89 & 21.17 & 22.61 & \\
\hline \multicolumn{5}{|l|}{ Intervention to promote participation in cancer screening } \\
\hline Personal invitation letters & 0.381 & 0.357 & 0.404 & \multirow[t]{5}{*}{$<0.05$} \\
\hline Household invitation letters & 0.221 & 0.202 & 0.241 & \\
\hline Home visits by community nurses & 0.061 & 0.049 & 0.072 & \\
\hline Screenings at medical offices & 0.502 & 0.478 & 0.526 & \\
\hline Free screenings for all age groups & 0.092 & 0.079 & 0.106 & \\
\hline \multicolumn{5}{|l|}{ Covariate } \\
\hline$\geq 30,000$ of total population in each municipality & 0.468 & 0.444 & 0.492 & - \\
\hline Total number of medical facilities per 1000 individuals aged 40 years and older & 1.183 & 1.147 & 1.219 & - \\
\hline \multicolumn{5}{|l|}{ Percentage of women (\%) } \\
\hline 40-49 years & 59.31 & 58.77 & 59.85 & \multirow[t]{4}{*}{$<0.05$} \\
\hline $50-59$ years & 59.69 & 59.14 & 60.25 & \\
\hline $60-69$ years & 56.09 & 55.83 & 56.35 & \\
\hline$\geq 70$ years & 60.35 & 60.15 & 60.55 & \\
\hline
\end{tabular}

Statistically significant difference based on ANOVA (analysis of variance) 


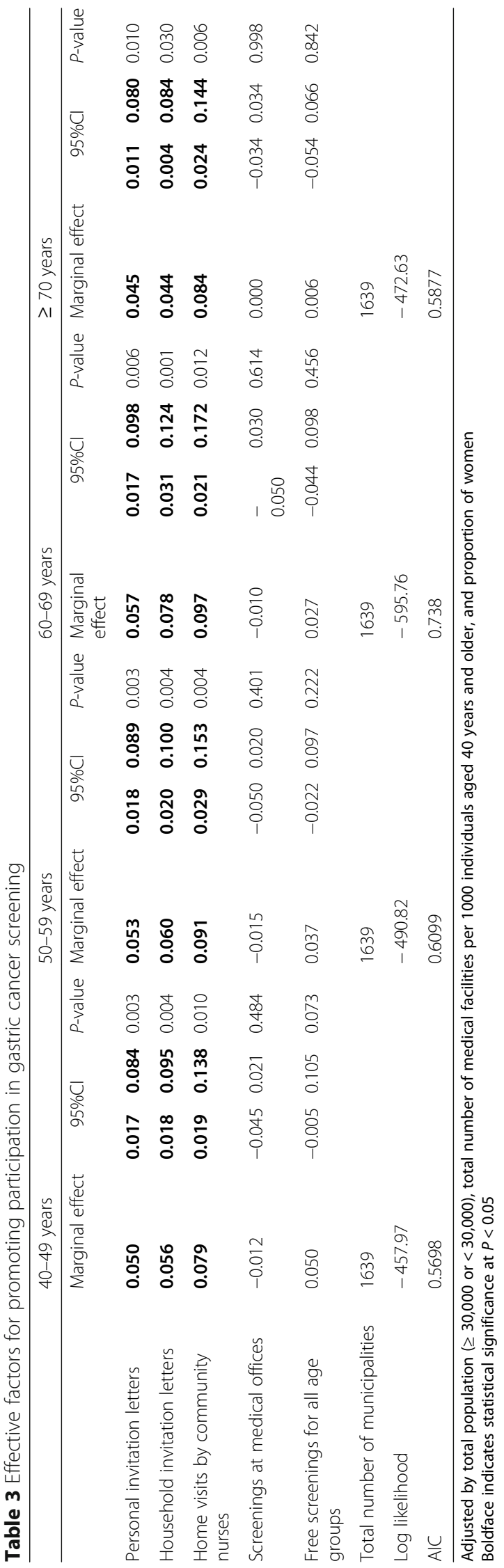




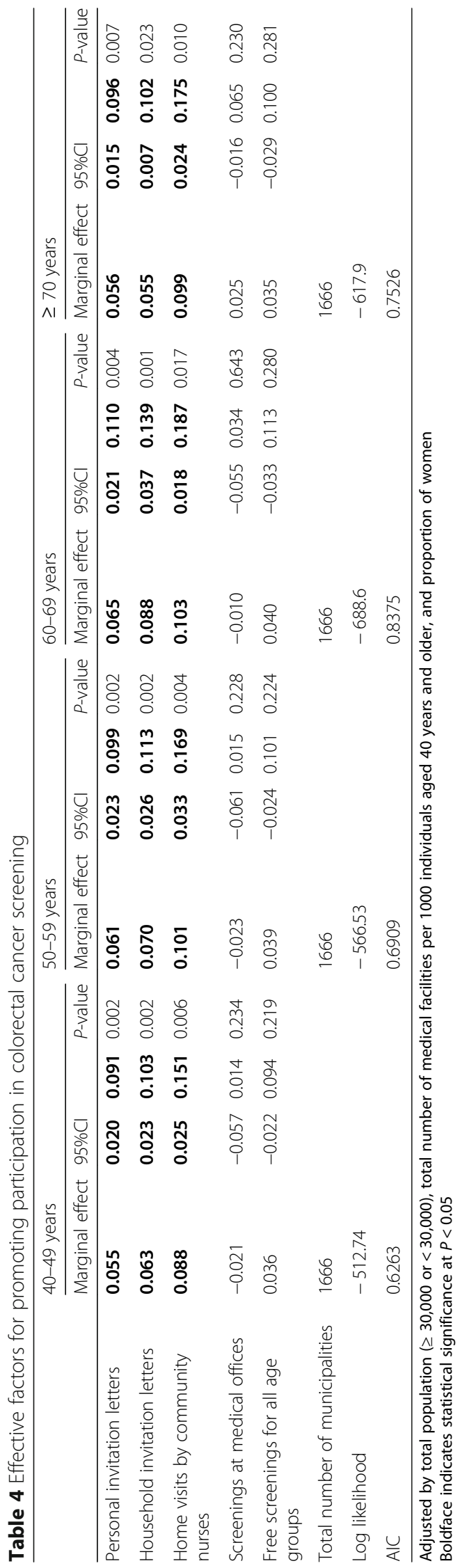


Colorectal cancer screening has been increasingly performed following breast and cervical cancer screenings; however, some countries have not yet introduced such screening or have remained in the pilot phase [3]. The coverage of invitation in the target age population is lower in colorectal cancer screening than in breast and cervical cancer screenings. The major reason for this lower coverage was resource limitations, particularly for total colonoscopy for diagnostic examination. Although the European Union defined the target population as 50-74 years, some countries (e.g., UK) intensively targeted a narrow range age group [3]. On the other hand, there is no upper age limit in the Czech Republic, Korea, and Japan [1-3]. For example in breast cancer screening, individuals who are in their 60s have continued participating even more and have maintained a higher participation rate than individuals who are in their 50s [23]. If the target age is not clearly defined, it is more favorable for the older age group to continue participating in cancer screening. Since an invitation letter has a similar effect on individuals who are in their 70 s, the priority of sending invitation letters targeting individuals who are in their $50 \mathrm{~s}$ and $60 \mathrm{~s}$ can be a solution for the efficient use of limited resources for gastric and colorectal cancer screenings.

There are several limitations in this study. First, although the response rates were high, several municipalities could not provide sufficient response or reply for analysis. Since the participation rates were higher in the Tohoku areas, their responses might have been affected. Additional analysis is needed after the recovery from the Great East Japan Earthquake, although some municipalities have not yet completely recovered. Second, our study is based on a provider perspective and not on individuals. However, individual participation is affected by various factors including cultural background. To improve the participation rate in cancer screening, these factors should be considered. Third, the subjects who were sent invitation letters were different among the municipalities. Some municipalities have already introduced a similar system, but such system might be different from the original call/recall system for sending invitation to all individuals of the target population for the cancer screening programs. Municipal governments often choose a limited population who will benefit from the local government health insurance and not those who have employment insurance. Therefore, all people cannot receive the same benefits of encouragement from invitation letters even if they have no opportunities to have cancer screening in their workplace. Finally, the Japanese health insurance system also influences participation in cancer screening. Although the Japanese health insurance does not cover cancer screening, all citizens can easily access medical services, with most of these serves covered by small co-payments [24]. Therefore, people do not feel obligated to avail of the municipal cancer screening programs. However, promotion strategies may become more effective under a different healthcare system. In Korea, the call/recall system is a major reason for the increase in the participation rate of cancer screening [15]. Therefore, it may be possible to generalize the results to other countries.

\section{Conclusion}

To clarify promotion strategies for increasing the participation rate in cancer screening among different age groups, 5 strategies were assessed on the basis of a national survey. Home visits were effective as a strategy, but their adoption was limited to small municipalities. Screening at medical offices and free screening were not effective in all age groups. Although personal and household invitation letters were effective strategies for promoting participation in cancer screening for all age groups, these strategies equally encouraged older people to participate in gastric and colorectal cancer screenings. If resources are limited particularly in sending invitation letters, priority should be given to individuals who are in their 50 s and 60 s for gastric and colorectal cancer screenings.

\section{Acknowledgements}

We are indebted to Dr. Edward F. Barroga (http://orcid.org/0000-0002-89202607), for reviewing and editing the English manuscript. We also thank Mr. Tomoki Kishi and Ms. Ikuko Tominaga for research assistance.

\section{Funding}

This study was supported by the National Cancer Center, Tokyo, Japan (Grant number: 29-A-16). The funder had no role in the conceptualization of the study design, data collection and analysis, decision to publish, or preparation of the manuscript.

Availability of data and materials

Available data set can be obtained from national data base (see Ethics approval and consent to participate)

\section{Authors' contributions}

$\mathrm{CH}$ designed the study. HS conducted the statistical analysis of the data. $\mathrm{CH}$ and HS wrote and made critical revisions to the article. Both authors read and approved the final manuscript.

Ethics approval and consent to participate

This study used national databases which are indicated below.

1. Ministry of Health, Labour and Welfare, Japan. Report on survey of implementation of cancer screening among the municipalities, 2010. http://www.mhlw.go.jp/stf/shingi/2r9852000002bifz-att/ 2r9852000002bimb.pdf. Accessed 1 Aug 2017.

2. Ministry of Health, Labour and Welfare, Japan. Report on regional public health services and health promotion 2010. http://www.e-stat.go.jp/SG1/ estat/GL08020103.do?_toGL08020103

\&listID=000001106542\&requestSender=dsearch. Accessed 1 Aug 2017.

3. Ministry of Internal Affairs and Communications, Japan. National Census 2010. http://www.e-stat.go.jp/SG1/estat/ GL08020101.do?_toGL08020101_\&tstatCode=000001039448\& requestSender =search. Accessed 1 Aug 2017.

4. Ministry of Health, Labour and Welfare. Medical Institute Survey in 2010. http://www.e-stat.go.jp/SG1/estat/ 
GL08020103.do?_toGL08020103_\&listID $=000001082979 \&$ requestSender=dsearch. Accessed 1 Aug 2017.

This information was not included personal information. Based on the Japanese guidelines for epidemiological studies developed by the national government, in the present study, secondary data from the national database were used, thus informed consent was waived.

\section{Ethics approval and consent to participate}

Not applicable.

\section{Competing interests}

The authors declare that they have no competing interests.

\section{Publisher's Note}

Springer Nature remains neutral with regard to jurisdictional claims in published maps and institutional affiliations.

\section{Author details}

'Division of Cancer Screening Assessment and Management, Center for Public Health Science, National Cancer Center, 5-1-1 Tsukiji Chuo-ku, Tokyo 104-0045, Japan. ${ }^{2}$ Faculty of Economics, Shiga University, 1-1-1 Baba-cho, Hikone, Japan.

\section{Received: 26 October 2017 Accepted: 19 March 2018}

Published online: 27 March 2018

\section{References}

1. Kim Y, Jun JK, Choi KS, Lee HY, Park EC. Overview of the national cancer screening programme and the cancer screening status in Korea. Asian Pac J Cancer Prev. 2011;12:725-73.

2. Hamashima C. Cancer screening guidelines and policy making: 15 years of experience in cancer screening guideline development in Japan. Jpn J Clin Oncol. 2018; https://doi.org/10.1093/jico/hyx190.

3. Basu P, Ponti A, Anttila A, Ronco G, Senore C, Vale DB, Segnan N, et al. Status of implementation and organization of cancer screening in The European Union Member States-Summary results from the second European screening report. Int J Cancer. 2018;142:44-56.

4. Steele RJC, Kostourou I, McClements P, Watling C, Libby G, Weller D, et al. Effect of repeated invitations on uptake of colorectal cancer screening using faecal occult blood testing: analysis of prevalence and incidence screening. BMJ. 2010;341:c5531.

5. Oshima A. A critical review of cancer screening programs in Japan. Int Technol Assess Health Care. 1994;10:346-58.

6. Cancer Registry and Statistics. Cancer Information Service, National Cancer Center, Japan. Participation rates in cancer screening based on report on regional public health services and health promotion (2006-2012). http:// ganjoho.jp/reg_stat/statistics/dl/index.html. Accessed 1 Aug 2017.

7. Ministry of Health, Labour and Welfare. Basic plan for cancer control 2012. http://www.mhlw.go.jp/bunya/kenkou/dl/gan_keikaku02.pdf. Accessed 1 Aug 2017.

8. Sano H, Goto R, Hamashima C. What is the most effective strategy for improving the cancer screening rate in Japan? Asian Pac J Cancer Prev. 2014;15:2607-12.

9. Ministry of Health, Labour and Welfare, Japan. Report on regional public health services and health promotion 2010. http://www.e-stat.go.jp/SG1/ estat/GL08020103.do?_toGL08020103_\&listID= $000001106542 \&$ requestSender=dsearch. Accessed 1 Aug 2017.

10. Ministry of Health, Labour and Welfare, Japan. Report on survey of implementation of cancer screening among the municipalities, 2010. http:// www.mhlw.go.jp/stf/shingi/2r9852000002bifz-att/2r9852000002bimb.pdf Accessed 1 Aug 2017.

11. Sabatino SA, Lawrence B, Elder R, Mercer SL, Wilson KM, DeVinney B, et al. Community Preventive Services Task Force. Effectiveness of interventions to increase screening for breast, cervical, and colorectal cancers: nine updated systematic reviews for the guide to community preventive services. Am J Prev Med. 2012:43:97-118.

12. Ministry of Internal Affairs and Communications, Japan. National Census 2010. http://www.e-stat.go.jp/SG1/estat/GL08020101.do? toGL08020101 \&tstatCode=000001039448\&requestSender=search. Accessed 1 Aug $201 \overline{7}$.
13. Ministry of Health, Labour and Welfare. Medical Institute Survey in 2010. http:// www.e-stat.go.jp/SG1/estat/GL08020103.do? toGL08020103 \&listlD= 000001082979\&requestSender=dsearch. Accessed 1 Aug 2017.

14. Sabatino SA, Lawrence B, Elder R, Mercer SL, Wilson KM, DeVinney B, et al. Effectiveness of interventions to increase screening for breast, cervical, and colorectal cancers: nine updated systematic reviews for the guide to community preventive services. Am J Prev Med. 2012;43:97-118.

15. Suh M, Song S, Cho HN, Park B, Jun JK, Choi E, et al. Trends in participation rates for the national cancer screening program in Korea, 2002-2012. Cancer Res Treat. 2017:49:798-806.

16. Walter LC, Lindquist K, Nugent S, Schult T, Lee SJ, Casadei MA, et al. Impact of age and comorbidity on colorectal cancer screening among older veterans. Ann Intern Med. 2009:150:465-73.

17. Lewis CL, Kistler CE, Amick HR, Watson LC, Bynum DL, Walter LC, et al. Older adults' attitudes about continuing cancer screening later in life: a pilot study interviewing residents of two continuing care communities. BMC Geriatr. 2006;6:10.

18. Torke AM, Schwartz PH, Holtz LR, Montz K, Sachs GA. Older adults and forgoing cancer screening: "I think it would be strange". JAMA Intern Med. 2013:173:526-31.

19. Mandelblatt JS, Cronin KA, Bailey S, Berry DA, de Koning HJ, Draisma G, et al. Effects of mammography screening under different screening schedules: model estimates of potential benefits and harms. Ann Intern Med. 2009;151: 738-47.

20. Schwartz LM, Woloshin S, Fowler FJ Jr, Welch HG. Enthusiasm for cancer screening in the United States. JAMA. 2004;291:71-8.

21. Stefanek ME. Uninformed compliance or informed choice? A needed shift in our approach to cancer screening. J Natl Cancer Inst. 2011;103:1821-6.

22. Schoenborn NL, Lee K, Pollack CE, Armacost K, Dy SM, Bridges JFP, et al. Older adults' views and communication preferences about cancer screening cessation. JAMA Intern Med. 2017:177:1121-8.

23. Törnberg S, Kemetli L, Svane G, Rosén M, Stenbeck M, Nyström L. Pattern of participation in a cohort aged 50-60 years at first invitation to the servicescreening programme with mammography in Stockholm county, Sweden. Prev Med. 2005:41:728-33.

24. Ikegami N, Yoo BK, Hashimoto H, Matsumoto M, Ogata H, Babazono A, et al. Japanese universal health coverage: evolution, achievements, and challenges. Lancet. 2011;378:1106-15.

\section{Submit your next manuscript to BioMed Central and we will help you at every step:}

- We accept pre-submission inquiries

- Our selector tool helps you to find the most relevant journal

- We provide round the clock customer support

- Convenient online submission

- Thorough peer review

- Inclusion in PubMed and all major indexing services

- Maximum visibility for your research

Submit your manuscript at www.biomedcentral.com/submit
Biomed Central 